\title{
PHF11 and DPP10: A Tale of Two Genes in Asthma
}

\author{
Ian M. Adcock Paul A. Kirkham \\ Airway Disease Section, National Heart and Lung Institute, Imperial College London, London, UK
}

Over the last 20 years, significant progress has been made in the identification of genes that could be related to asthma. In 2003, the positional cloning of 2 genes that modify the risk of developing asthma was announced: plant homeodomain finger protein 11 (PHF11) and dipeptidyl-peptidase 10 (DPP10). Single nucleotide polymorphisms (SNPs) in the PHF11 gene [1] were associated with high IgE levels and with severe asthma in an Australian and 2 UK cohorts. In similar patients, the same group also reported an association between SNPs in the initial exons of the DPP10 gene and asthma, particularly severe asthma [2]. Other studies have attempted to reproduce these associations between PHF11 and DPP10 in asthma [3]. Examination of over 7,500 Caucasian subjects in the British 1958 Birth Cohort DNA archive provided evidence for polymorphisms producing small (OR 1.1 per allele) but statistically significant increases in asthma risk in DPP10 but not in PHF11 [4]. In contrast, analysis in 2 distinct asthma probands in the USA (European-American and Costa-Rican children) [5] reported only weak evidence for locus-level replication in the PHF11 locus with asthma. In addition, there was no overlap in the associated SNP across the 2 cohorts. Finally, although several marginally significant associations were found between PHF11 and spirometry measures and asthma in 1 of 2 Western Australian populations, these did not remain significant with adjustment for multiple testing [6].

In this issue of Respiration, Gao and colleagues [7] confirm the presence of genetic variants in PHF11 and
DPP10 for asthma susceptibility and related traits in an adult Han Chinese population of asthmatics with high IgE levels. Two markers in PHF11 (rs1046295 and rs16659) were associated with asthma and 1 marker (rs11619265) with the percentage of blood eosinophils. Although no markers in DPP10 were directly associated with asthma, a strong association was seen with 1 DPP10 marker (rs10208402) and log total IgE and the percentage of blood eosinophils. Further, a weaker association with another DPP10 marker (rs1430090) and forced expiratory volume in $1 \mathrm{~s}$ was reported. This association is supported by haplotype analysis where 1 haplotype in PHF11 was protective against asthma. Previously, these SNPs had been associated with asthma in Caucasian subjects, particularly in children with more severe disease.

Further analysis of the Han Chinese population is needed to determine whether the SNPs reported here are linked to asthma severity, treatment or environmental pollutants such as cigarette smoking. Thirty percent of the asthmatic Han population were smokers which beg the question as to whether these genes may also be associated with chronic obstructive pulmonary disease. Cigarette smoke is a great source of oxidants and also induces oxidant stress in the airways [8]. Oxidative stress can also affect DNA methylation, thereby altering gene expression patterns [9], and these epigenetic changes may account for some of the differences reported in distinct populations and cohorts relating to PHF11 and DPP10 in asthma.

\section{KARGER}

Fax +4161306 1234 E-Mail karger@karger.ch www.karger.com
(C) 2009 S. Karger AG, Basel 0025-7931/10/0791-0014\$26.00/0

Accessible online at: www.karger.com/res
Prof. Ian M. Adcock

Respiratory Cell and Molecular Biology, Airway Disease Section

National Heart and Lung Institute, Imperial College London, Dovehouse Street London SW3 6LY (UK)

Tel. +44 207351 8878, Fax +44 207351 8126, E-Mail ian.adcock@imperial.ac.uk 
Replication of an association between PHF11 and DPP10 with asthma provides strong evidence for a role of these genes in the disease. What could be the function of these 2 genes in asthma? PHF11 is a transcription factor with numerous splice variants observed in both $\mathrm{T}$ and $\mathrm{B}$ cells [1] and can upregulate the expression of Th1 cytokines from T cells. The effect of PHF11 over expression and knockdown using siRNA in primary CD4+ T cells and Jurkat $\mathrm{T}$ cells has been investigated [10]. Increased PHF11 expression in Th1 cells was associated with increased interferon- $\gamma$ and interleukin-2, possibly through a physical and functional interaction with the p65 subunit of nuclear factor- $\kappa \mathrm{B}$. Conversely, reduced PHF11 expression is associated with enhanced Th2 responses, and low PHF11 expression may account for the high Th2 cytokine response seen in atopic dermatitis [10].

PHF11 could also act on B cells to cause class switching perhaps mediated through epigenetic events or indirectly through the associated methylase SETDB2 [11]. Whether PHF11 or SETDB2 expression is reduced in specific cells within the airways of asthmatic patients awaits further experimentation.

Unlike other DPP family members, DPP10 is unable to cleave terminal dipeptides from asthma-related cytokines and chemokines such as eotaxin and RANTES [12]. In animal models of asthma, DPP10 is localized to the airway epithelium, and its expression is increased following ovalbumin challenge [13]. In preliminary data, we have found that DPP10 is preferentially expressed in the epithelium of asthmatic and chronic obstructive pulmonary disease airways [14]. This suggests that alternative mechanisms for the role of DPP10 in asthma must be sought. In neurones, DPP10 forms part of the A-type $\mathrm{K}+(\mathrm{Kv} 4)$ ion channel complex [15]. In these cells, it can also act as a chaperone protein and traffics $\mathrm{Kv} 4$ to the plasma membrane, and thereby, can perform a role as a general modulator of voltage-gated $\mathrm{K}(+)$ channel inactivation. There is increasing awareness of an important role of ion channels in asthma which raises the question as to whether DPP10 has a chaperone role for other ion channels in airway cells. Further work to examine the effects of overexpression and/or knockdown of DPP10 in airway epithelial cells is needed. The interaction between/with environmental pollution and/or barn dust extracts may reveal unforeseen actions of DPP10 as well.

DPP10 may also act as a more general chaperone and may interact with other important signalling molecules such as hsp90 and associated proteins, and thereby, modulate apoptosis [14]. Again, modulation of DPP10 expres- sion in airway epithelial cells may determine the potential of DPP10 to affect cell apoptosis and/or drug sensitivity under inflammatory conditions.

Evidence suggests that distinct phenotypes of asthma may underlie adult and childhood asthma which may be associated with separate genotypes [16]. Therefore, the lack of children in the Han study may affect the observed associations. The differences found between the Caucasian and Han Chinese populations may reflect real differences in the genetic effects of DPP10 and PHF11 in these asthmatics or may alternatively reflect an effect of the local environment on gene function. The high proportion of smokers in the Han population suggests that the effect of cigarette smoke on the actions of these genes may prove informative.

These results highlight the challenges of replicating genetic associations in complex traits such as asthma, even for genes identified by linkage analysis. Furthermore, although the data suggest that DPP10 and PHF11 influence IgE levels, blood eosinophilia and/or asthma risk in 2 distinct populations, the overall effects driven by any given locus are small, and genotyping of multiple polymorphisms in many genes will be needed to define a full genetic profile for disease risk [3]. In addition, in many of these genetic replication studies, only a few genes at any particular time are examined, and this may preclude an examination of epistatic effects whereby a gene determines whether or not a trait is expressed [3]. A combination of genetics along with consideration of epistatic interactions and epigenetic changes may be needed before full sense of the impact of these results upon clinical medicine is elucidated.

References

PHF11 and DPP10: A Tale of Two Genes in Asthma 
3 Weiss ST, Raby BA, Rogers A: Asthma genetics and genomics 2009. Curr Opin Genet Dev 2009;19:279-282.

4 Blakey JD, Sayers I, Ring SM, Strachan DP, Hall IP: Positionally cloned asthma susceptibility gene polymorphisms and disease risk in the British 1958 Birth Cohort. Thorax 2009;64:381-387.

5 Hersh CP, Raby BA, Soto-Quiros ME, Murphy AJ, Avila L, Lasky-Su J, Sylvia JS, Klanderman BJ, Lange C, Weiss ST, Celedon JC: Comprehensive testing of positionally cloned asthma genes in two populations. Am J Respir Crit Care Med 2007;176:849-857.

6 McClenaghan J, Warrington NM, Jamrozik EJ, Hui J, Beilby JP, Hansen J, de Klerk NH, James AL, Musk WD, Palmer LJ: The PHF11 gene is not associated with asthma or asthma phenotypes in two independent populations. Thorax 2009, Epub ahead of print

7 Gao J, Li W, Willis-Owen SA, Jiang L, Ma Y, Tian X, Moffatt M, Cookson W, Lin Y, Zhang Y: Polymorphisms of PHF11 and DPP10 are associated with asthma and related traits in a Chinese population. Respiration 2010; 79:17-24.
8 Rahman I, Adcock IM: Oxidative stress and redox regulation of lung inflammation in COPD. Eur Respir J 2006;28:219-242.

$\checkmark 9$ Hitchler MJ, Domann FE: An epigenetic perspective on the free radical theory of development. Free Radic Biol Med 2007;43:10231036.

10 Clarke E, Rahman N, Page N, Rolph MS, Stewart GJ, Jones GJ: Functional characterization of the atopy-associated gene PHF11. J Allergy Clin Immunol 2008;121:11481154.

11 Petersen-Mahrt S: DNA deamination in immunity. Immunol Rev 2005;203:80-97.

12 Qi SY, Riviere PJ, Trojnar J, Junien JL, Akinsanya KO: Cloning and characterization of dipeptidyl peptidase 10, a new member of an emerging subgroup of serine proteases. Biochem J 2003;373:179-189.
13 Schade J, Stephan M, Schmiedl A, Wagner L, Niestroj AJ, Demuth HU, Frerker N, Klemann C, Raber KA, Pabst R, von Hörsten S: Regulation of expression and function of dipeptidyl peptidase 4 (DP4), DP8/9, and DP10 in allergic responses of the lung in rats. J Histochem Cytochem 2008;56:147-155.

14 Tsaprouni L, Ito K, Cookson WO, Moffatt MF, Barnes PJ, Adcock IM: Functional genomics of DPP10. Protein characterization and its association with asthma and COPD. Am J Respir Crit Care Med 2007; 175:A387.

15 Maffie J, Rudy B: Weighing the evidence for a ternary protein complex mediating A-type $\mathrm{K}+$ currents in neurons. J Physiol 2008;586: 5609-5623.

-16 Chanez P, Wenzel SE, Anderson GP, Anto JM, Bel EH, Boulet LP, Brightling CE, Busse WW, Castro M, Dahlen B, Dahlen SE, Fabbri LM, Holgate ST, Humbert M, Gaga M, Joos GF, Levy B, Rabe KF, Sterk PJ, Wilson SJ, Vachier I: Severe asthma in adults: what are the important questions? J Allergy Clin Immunol 2007;119:1337-1348. 